\title{
Effect of Biological Contact Filters (BCFs) on Membrane Fouling in Drinking Water Treatment Systems
}

\author{
Susumu Hasegawa ${ }^{1, *}$, Takuya Iwamoto ${ }^{1}$, Taro Miyoshi ${ }^{1}$, Sosuke Onoda ${ }^{2}$, Kazushi Morita ${ }^{3}$, \\ Ryosuke Takagi ${ }^{1}$ and Hideto Matsuyama ${ }^{1, *}$ \\ 1 Center for Membrane and Film Technology, Department of Chemical Science and Engineering, \\ Graduate School of Engineering, Kobe University, 1-1 Rokkodai-cho, Nada-ku, Kobe 657-8501, Japan; \\ t.iwamoto@kobe-u.ac.jp (T.I.); t.miyoshi@kobe-u.ac.jp (T.M.); takagi@harbor.kobe-u.ac.jp (R.T.) \\ 2 Research and Development Planning Department, Technical Development Division, \\ Technical Research Center, Kobelco Eco-Solutions Co., Ltd., 1-1-4 Murotani, Nishi-ku, Kobe 651-2241, Japan; \\ s.onoda@kobelco-eco.co.jp \\ 3 Kobe City Waterworks Bureau, 37-1 Kusudani-cho, Kobe 652-0004, Japan; \\ kazushi_morita@office.city.kobe.lg.jp \\ * Correspondence: s.hasegawa@people.kobe-u.ac.jp (S.H.); matuyama@kobe-u.ac.jp (H.M.); \\ Tel.: +81-78-803-6610 (S.H.); +81-78-803-6180 (H.M.)
}

Received: 5 October 2017; Accepted: 12 December 2017; Published: 15 December 2017

\begin{abstract}
Membrane fouling is a serious problem in drinking water treatment systems. Biological contact filters $(\mathrm{BCFs})$ are often used as a pretreatment to remove ammonia, dissolved organic matter (DOM), and metal ions such as iron and manganese. In this study, the effect of BCF as a pretreatment for membrane fouling was evaluated using a laboratory-scale mini module consisting of a mini BCF column and a mini MF column. Initially, it was confirmed that the main foulant was a biopolymer (at low concentration) in the raw water. Subsequently, the biopolymer concentrations in the BCF influent and effluent were measured with the excitation emission matrix (EEM) fluorescence spectroscopy and the liquid chromatograph organic carbon detector (LC-OCD). The fouling potential of the $\mathrm{BCF}$ influent and effluent was also measured to evaluate MF membrane fouling rate. The results demonstrate that application of the $\mathrm{BCF}$ reduced the biopolymer concentration of the effluent and reduced membrane fouling. The effect of $\mathrm{BCF}$ was also established in an actual drinking water treatment plant. It was found that optimizing the contact time of raw water with the $\mathrm{BCF}$ was crucial to reduce membrane fouling.
\end{abstract}

Keywords: biological contact filter (BCF); membrane fouling; water treatment; foulant; biopolymer; excitation emission matrix (EEM); liquid chromatograph organic carbon detector (LC-OCD)

\section{Introduction}

Microfiltration (MF) and ultrafiltration (UF) systems have been adopted in drinking water treatment systems to remove suspended solids and pathogenic microorganisms (e.g., cryptosporidium) from raw water. However, these membrane systems cannot remove dissolved matter such as substances that cause foul smell and dissolved metals. Thus, biological contact filters (BCFs) have been employed as a pretreatment system [1]. Compared with common pretreatment methods like coagulation and active carbon adsorption, the advantage of $\mathrm{BCF}$ treatment is that it can remove dissolved mater without chemicals and does not produce sludge [2]. Moreover, cleaning the filter media in BCF columns is straightforward, involving just weekly chemical-free water flashing and air bubbling. This process is extremely safe and easy to maintain. In contrast, although coagulation and active carbon adsorption 
are simple processes, the former method produces a large amount of sludge and the latter method requires expensive media.

$\mathrm{BCF}$ is a filter media onto which microorganisms are attached. When raw water such as river water flows through the BCF column, ammonia and dissolved organic matter (DOM), including those that produce foul smell, are oxidized and removed by the microorganisms attached to the filter media [3]. Additionally, iron and manganese are also oxidized to insoluble metal oxides and removed by autotrophic bacteria [4]. Microorganisms in the BCF trap the oxidized matter, thereby restricting its flow to the next process (MF or UF). Regarding the effect of BCF treatment on biopolymers, two types of effects are expected. First, biopolymers may be decomposed by microorganisms in the BCF column. Second, biopolymer may be produced by microorganisms as metabolites. It has been reported that the main foulants in water treatment systems are biopolymers [5,6]. Despite these on-going issues, few reports have emerged concerning the influence of $\mathrm{BCF}$ treatment on membrane fouling.

In this study, we investigated the effect of BCF pretreatment on membrane fouling in a drinking water treatment system. Initially, we confirmed that the main foulants were biopolymers. Then, we investigated the effect of BCF treatment on changing in the biopolymer concentration in the effluent of the BCF column to prevent membrane fouling. Essentially, the performance of BCF is based on biological reactions. Thus, the influences of temperature and the contact time of the raw water in the BCF column were also investigated.

\section{Materials and Methods}

\subsection{Water Sample}

In this study, the feed water was sampled from the Motoyama drinking water treatment plant in Kobe, Japan. In this plant, a MF system capable of treating $2000 \mathrm{~m}^{3}$ /day of water has been introduced since 2010. Raw water taken from the Sumiyoshi River is fed to the BCF as a pretreatment for the membrane system, and the BCF effluent is provided to the MF system directly. The linear velocity in the BCF is $\sim 75 \mathrm{~m} /$ day with down flow. The filter media in BCF is washed weekly by water flushing and air bubbling.

The water sample for our study was taken from the BCF influent and effluent in the Motoyama plant and used without any pretreatment.

\subsection{Test Equipment}

In order to confirm the identity of the main foulants in raw water from the Sumiyoshi River, we investigated the relationship between the water composition and membrane fouling using laboratory-scale mini test equipment. The mini test equipment consisted of a mini BCF column and mini MF modules, as shown in Figure 1.

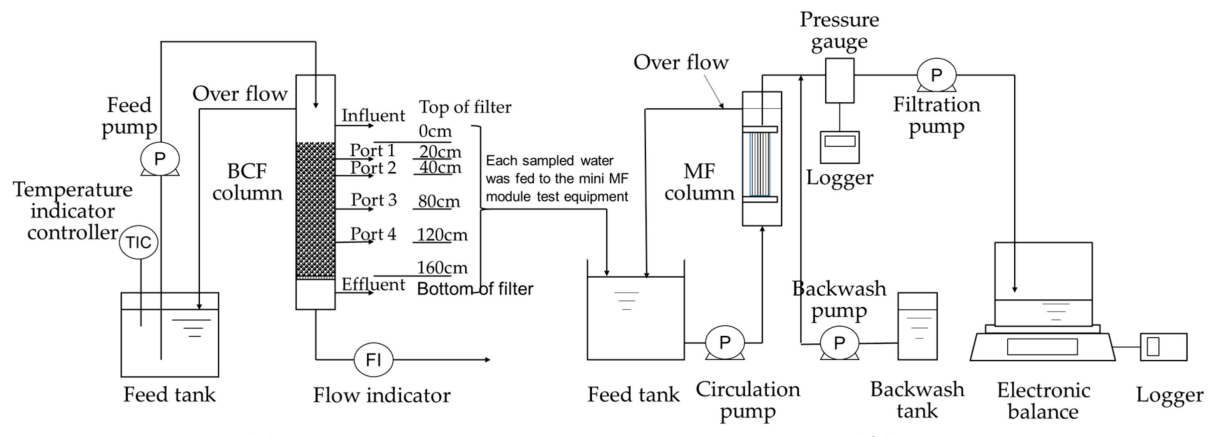

(a)

(b)

Figure 1. Schematic drawing of the test equipment employed in this study. (a) Mini biological contact filter (BCF) column; (b) Mini Microfiltration (MF) module. 
The mini BCF column was a cylindrical pipe made from transparent acrylic with an inner diameter and height of $32 \mathrm{~mm}$ and $1.8 \mathrm{~m}$, respectively. Ceramic beads $1.4 \mathrm{~mm}$ in diameter and $2.8 \mathrm{~mm}$ in length, onto which the microorganisms were adhered, were filled in the column to a height of $1.6 \mathrm{~m}$. The raw water was fed into the column with down flow at a superficial velocity of $75 \mathrm{~m} /$ day. To consider the influence of contact time in the BCF column, four nozzles were set at 20,40, 80, and $120 \mathrm{~cm}$ from the top surface of the filter media, which is equivalent to $3.75,7.5,15$, and $22.5 \mathrm{~min}$ of contact time of raw water with filter media, respectively. To consider the effect of water temperature, a heater or condenser was placed in the feed tank to control the water temperature at $5 \pm 0.2{ }^{\circ} \mathrm{C}$, which corresponds to the average winter water temperature.

The water sample taken from the mini BCF column under each condition was fed to the mini MF module as a feed. The mini MF module consisted of three hollow fibers of polyvinylidene fluoride (PVDF) (Asahi Kasei Chemicals, Tokyo, Japan) of $12 \mathrm{~cm}$ in effective length. The fiber pore size was $0.08 \mu \mathrm{m}$, and its outer and inner diameters were $1.25 \mathrm{~mm}$ and $0.69 \mathrm{~mm}$, respectively. One end of the module was closed with resin, while the other end was open to draw out the permeated water. The effective surface area of the module was $\sim 15 \mathrm{~cm}^{2}$. The mini module was immersed in the cylindrical column of $25 \mathrm{~mm}$ in inner diameter and $40 \mathrm{~cm}$ in length. The sample water was circulated through the MF column by a micro tube pump at a superficial velocity of $100 \mathrm{~m} /$ day. The permeated water was drawn from the open side of the mini module by another micro tube pump. Table 1 shows the operating conditions of this system. The actual commercial plant employed in this study (i.e., the Motoyama drinking water treatment plant) utilizes external-type pressure for its use, whereas the mini module test equipment utilizes a vacuum for permeate withdrawal. However, this difference is unlikely to affect membrane fouling. Sodium hypochlorite $(\mathrm{NaClO})$ was injected into the backwashing pipe line of the mini module test equipment since, in the actual plant, $\mathrm{NaClO}$ is used to sterilize the inside of the pipe line through which permeated water flows, and it also cleans the membrane. Additionally, although the actual plant module has an air bubbling system to remove sediments on the membrane surface, the test equipment did not have one. Thus, according to the method reported by Miyoshi et al. [7], the membrane surface was wiped with a sponge to remove the sediments once a week and at the end of the test.

Table 1. Specification of the MF mini module and operating conditions.

\begin{tabular}{cc}
\hline \multicolumn{2}{c}{ Specifications of Membrane } \\
\hline Material & $\begin{array}{c}\text { polyvinylidene fluoride (PVDF) } \\
\text { Pore size } \\
\text { Effective area }\end{array}$ \\
\multicolumn{1}{c}{ Operating Conditions } \\
\hline \multicolumn{2}{c}{$15 \mathrm{~cm}^{2}$} \\
\hline Filtration flux & $1.5 \mathrm{~m}^{3} /\left(\mathrm{m}^{2} \cdot\right.$ day) \\
Backwash flux & $2.25 \mathrm{~m}^{3} /\left(\mathrm{m}^{2} \cdot\right.$ day) \\
Backwash water & permeate water with $5 \mathrm{ppm} \mathrm{NaClO}$ \\
Backwash repetition & 1 min every 30 min \\
Wiping with sponge & once $/$ week and at test end \\
\hline
\end{tabular}

\subsection{Experimental Methods}

\subsubsection{Mini Biological Contact Filter (BCF) Column Test}

To begin the mini BCF column test, $20 \mathrm{~L}$ of BCF effluent taken from the actual plant was circulated through the mini BCF column at a superficial velocity of $75 \mathrm{~m}$ /day with down flow operation for one week at room temperature $\left(\sim 20^{\circ} \mathrm{C}\right)$. During this time, microorganisms within in the BCF effluent attached to the filter media in the mini BCF column. Then, the mini BCF feed water was changed to $20 \mathrm{~L}$ of BCF influent taken from the actual plant and circulated through the column. The mini BCF 
feed water was replaced once per week, and the operation continued for two months to stabilize the BCF column.

Subsequently, $20 \mathrm{~L}$ of BCF influent taken from the actual plant was circulated through the mini $\mathrm{BCF}$ test column for more than two weeks. The temperature of the $\mathrm{BCF}$ influent was controlled at $5{ }^{\circ} \mathrm{C}$ to acclimate the microorganisms to low temperature, which corresponded to the actual river water temperature during the season the tests were performed. The mini $\mathrm{BCF}$ feed water was replaced once per week. After more than two weeks of acclimation to $5{ }^{\circ} \mathrm{C}$, the influence of the water temperature on the process was investigated by passing each new water sample controlled at $5,10,15$, and $20^{\circ} \mathrm{C}$ to the mini BCF column for more than $60 \mathrm{~min}$. The processed water from each port was then collected to determine to effect of various contact times on the sampled water.

\subsubsection{Filtration Test of Sampled Water}

In order to evaluate the fouling potential of water sampled from the actual plant, the filtration test was performed using the mini MF module test equipment shown in Figure 1b. Sampled water was circulated through the mini MF column in which the mini MF module was set. The permeated water was drawn through the mini MF module at a constant velocity of $1.5 \mathrm{~m}^{3} /\left(\mathrm{m}^{2} \cdot\right.$ day $)$. The mini MF module was backwashed with permeated water mixed with $\mathrm{NaClO}(5 \mathrm{ppm})$ for 1 min every $30 \mathrm{~min}$ to reduce membrane fouling. The transmembrane pressure (TMP) was monitored for five days.

The fouling potential of the sampled water was evaluated by its membrane filtration resistance $(1 / \mathrm{m}), R m(t)$, which is defined by Equation (1).

$$
R m(t)=\Delta P(t) /(\mu \cdot J)
$$

where $\Delta P(t)$ is the transmembrane pressure (Pa) at time $t$ (day), $J$ is the filtration flux $(\mathrm{m} / \mathrm{s})$, and $\mu$ is the viscosity (Pa.s) of the sample water. Note that larger values of $R m(t)$ indicate a higher fouling potential of the sampled water.

\subsubsection{Foulant Extraction Method}

After the filtration test, the fouled mini MF module was removed from the casing column. The membrane surface was then wiped carefully to remove the reversible fouling materials, and the membrane was immersed in a $\mathrm{NaOH}$ solution ( $\mathrm{pH} 12$ ) for $24 \mathrm{~h}$ to extract the organic foulants. Although $\mathrm{NaClO}$ (5 ppm) was used for the backwashing step, $\mathrm{NaOH}$ was used to extract the organic foulants because $\mathrm{NaClO}$ may cause their oxidation.

\subsection{Analytical Method}

\subsubsection{Excitation Emission Matrix (EEM) Fluorescence Spectroscopy}

In order to characterize the dissolved organic matter (DOM) in the influent and effluent of the mini BCF column, EEM measurements were performed. Prior to the EEM measurements, however, all samples were filtered through a $0.45 \mu \mathrm{m}$ hydrophilic polytetrafluoroethylene membrane (DISMIC 13HP045AN, ADVANTEC, Tokyo, Japan). An EEM spectrometer measured the EEM fluorescence (Aqualog, HORIBA Advanced Techno Co., Ltd., Kyoto, Japan). The excitation light was set from 220 to $800 \mathrm{~nm}$ and irradiated for $1 \mathrm{~s}$ at intervals of $3 \mathrm{~nm}$. As in Chen et al. [8], when evaluating the three-dimensional fluorescence spectra, the spectra were divided into five domains and the sum of the fluorescence intensity within each domain was calculated.

\subsubsection{Liquid Chromatograph Organic Carbon Detector (LC-OCD)}

LC-OCD measurements were performed to analyze the concentration of natural organic matter (NOM) in the influent and effluent of the mini BCF column. Before the LC-OCD measurements, the same type of membrane filter used for the EEM measurements was used to filter all of the samples. 
The organic carbon content was measured with a Model 8 DOC-LABOR instrument (DOC-LABOR, Karlsruhe, Germany). The chromatographic column we used is a hydrophilic week cation exchange resin (TOYOPEARL HW-50, Tosoh, Tokyo, Japan). The NOMs separated in the chromatographic column were oxidized by UV in the thin film reactor. Then, $\mathrm{NOMs}$ were converted into $\mathrm{CO}_{2}$ by acidification liquid and removed from the feed. The concentration of NOMs were determined as the concentration of $\mathrm{CO}_{2}$ by non-diffusion infrared detector. The mobile phase consisted of a phosphorus acid buffer at $\mathrm{pH} 6.58$ with sodium dihydrogen phosphate and disodium hydrogenphosphate (Sigma-Aldrich Japan, Tokyo, Japan), and the acidification liquid consisted of a phosphorus acid buffer at $\mathrm{pH} 1.5$ with phosphoric acid and potassium peroxodisulfate (Sigma-Aldrich Japan, Tokyo, Japan). The mobile phase was injected at a flow rate of $1.1 \mathrm{~mL} / \mathrm{min}$, and the quantity of the sample injection was set to $1000 \mu \mathrm{L}$. The total retention time was set at $130 \mathrm{~min}$. The concentration of NOMs was calculated using the software chromCALC (DOC-LABOR, Karlsruhe, Germany) customized to our system.

\section{Results and Discussion}

\subsection{Identification of Foulants}

To identify the foulants in the river water with the MF membrane, filtration tests of the BCF influent of an actual plant along the Sumiyoshi River were performed for two months using the mini MF module under the conditions listed in Table 1. After this period, the fouled mini MF module was removed from the casing column and the organic foulants were extracted by the procedure outlined in Section 2.3.3. The BCF influent and the foulants extracted from membrane surface were then subjected to EEM and LC-OCD analyses.

Figure 2 shows the results of the EEM analysis of the (a) BCF influent and (b) fouling material extracted from the MF membrane after two months of operation. According to the classification by Chen et al. [8], humic substances, including fulvic acid-like (Region III) and humic acid-like (Region V) materials, were the major components in the BCF influent; peaks corresponding to proteins (classified in Regions I, II, and IV) were scarcely detected. However, peaks corresponding to proteins were clearly detected in the fouling material extracted from membrane surface. The protein-like materials are contained in the river water, even though their concentration was negligibly low. They will also be produced by bacteria attached on the membrane surface when the biofouling takes place. However, in our experiment, the filtration test was carried out for five days with backwashing for $1 \mathrm{~min}$ every $30 \mathrm{~min}$. So, the biofouling may scarcely take place. Thus, it is difficult to identify where these protein-like materials come from, the bacteria attached to the membrane surface, and/or the river water.
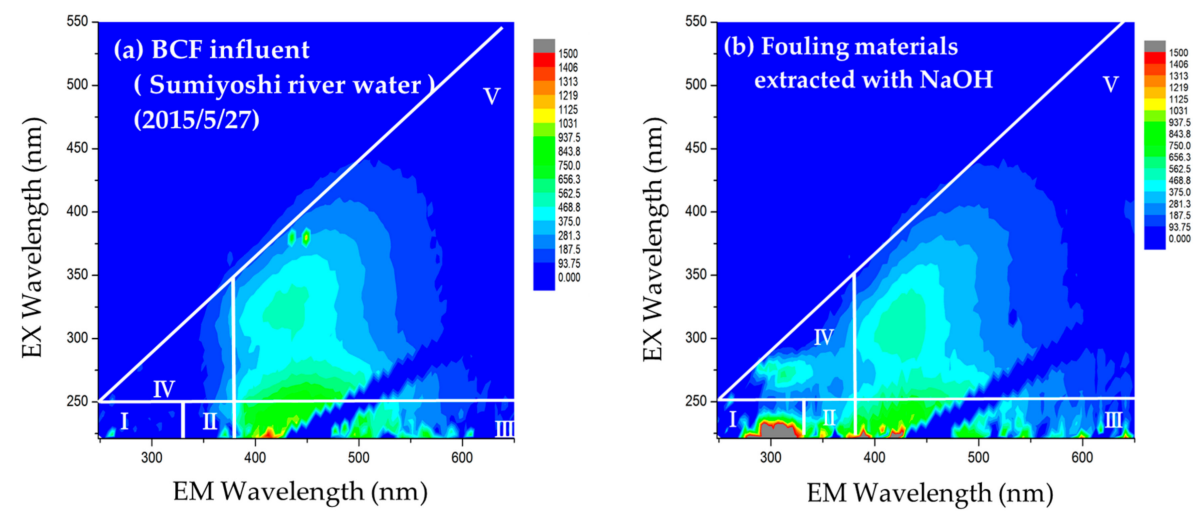

Figure 2. Excitation and emission matrix of (a) biological contact filter (BCF) influent and (b) fouling material extracted with NaOH. I: Aromatic Protein I; II: Aromatic Protein II; III: Fulvic acid-like; IV: Soluble microbial by-products; V: Humic acid-like. 
Figure 3 shows the results of the LC-OCD analysis of the (a) BCF influent and (b) fouling material extracted from the fouled MF membrane. As with the EEM results, it is clear from Figure 3a that the major component of the organic material in the BCF influent is the humic substances, which had a retention time of $43 \mathrm{~min}$. In the fouling material, however, the concentration of biopolymers [7], located at a retention time of $31 \mathrm{~min}$, was the highest or comparable with the humic substances, as shown in Figure 3b. This result is consistent with that of EEM. Overall, these results demonstrate that a very small amount of biopolymer in the BCF influent strongly influenced fouling of the MF membrane.
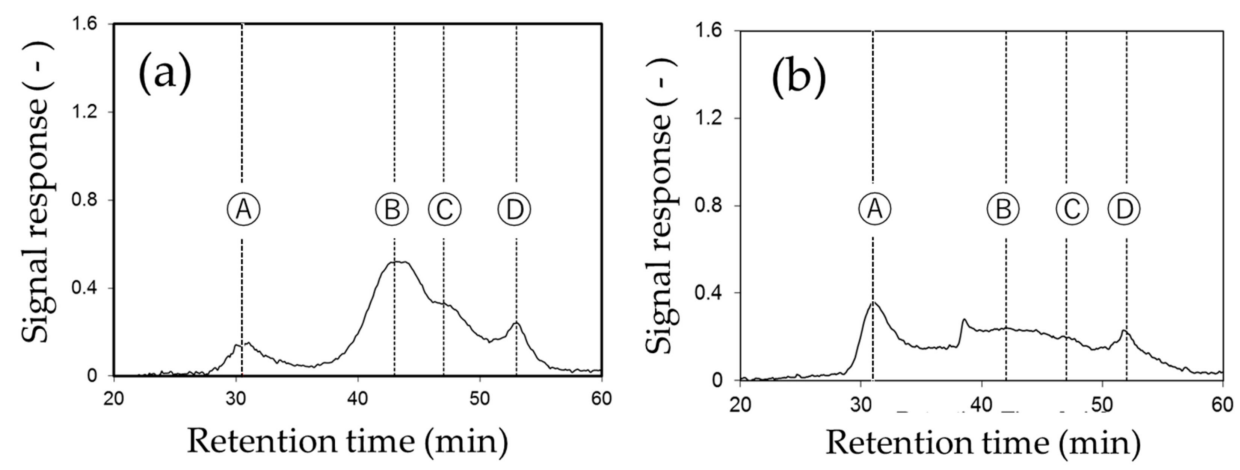

Figure 3. Chromatograph of (a) BCF influent and (b) fouling material measured by liquid chromatograph-organic carbon detector (LC-OCD). (A) Biopolymer; (B) Humic substances; (C) Building blocks; and (D) Acids.

\subsection{Effect of BCF Pretreatment on MF Membrane Fouling}

Because $\mathrm{BCF}$ is a biological process, it is reasonable to consider that the water temperature and contact time between the water and the microorganisms in the BCF affect its performance. To this end, we investigated the influence of these variables following the procedure outlined in Section 2.3.1. The focus of these investigations involved the biopolymer and humic substances, since these were identified in Section 3.1 as the main foulants.

Figure $4 \mathrm{a}$,b show the concentrations, as measured by LC-OCD, of the humic substances and biopolymers in the mini BCF effluent as a function of contact time, respectively. The data at zero contact time corresponds to the raw feed water. It is clear from Figure $4 \mathrm{a}$ that most of the humic substances were not removed by the BCF pretreatment; the concentrations were essentially identical regardless of the contact time. By comparison, the biopolymer was removed $\sim 30 \%$ by the BCF pretreatment, even at the very low temperature of $5{ }^{\circ} \mathrm{C}$. In addition, Figure $4 \mathrm{~b}$ shows that the biopolymer concentration first decreased with the contact time and then increased after showing a concentration minimum at $15 \mathrm{~min}$ contact time for all temperatures investigated.

The filtration resistance (Equation (1)) of each water sample taken from the BCF column test was calculated using the $20 \mathrm{~h}$ filtration data to evaluate their fouling potential. Figure 5 shows the change of filtration resistance of the membrane as a function of contact time at each operation temperature. As seen, the change of filtration resistance is similar to the change of biopolymer concentration. This result suggests that the biopolymer is the most important component related to membrane fouling in this drinking water treatment system. It is clear from Figures $4 \mathrm{~b}$ and 5 that the BCF is an effective pretreatment method for reducing membrane fouling.

It is found from Figures $4 \mathrm{~b}$ and 5 that the biopolymer concentration and filtration resistance increase at contact times longer than $15 \mathrm{~min}$. In the mini BCF column, biopolymers may be decomposed by microorganisms, and meanwhile produced as metabolites. Thus, the biopolymer concentration in the mini BCF effluent is determined by the competition of two opposite phenomena, decomposing and producing biopolymer. The concentration of biopolymer produced by microorganisms probably exceeded the concentration of biopolymer decomposed by microorganisms at contact times longer than $15 \mathrm{~min}$. Then, the biopolymer concentration increased and the filtration resistance increased at 
contact times longer than $15 \mathrm{~min}$. Previous studies have reported that longer contact times in BCFs lead to superior biopolymer removal $[9,10]$. However, the results presented herein suggest that optimizing the contact time is crucial.
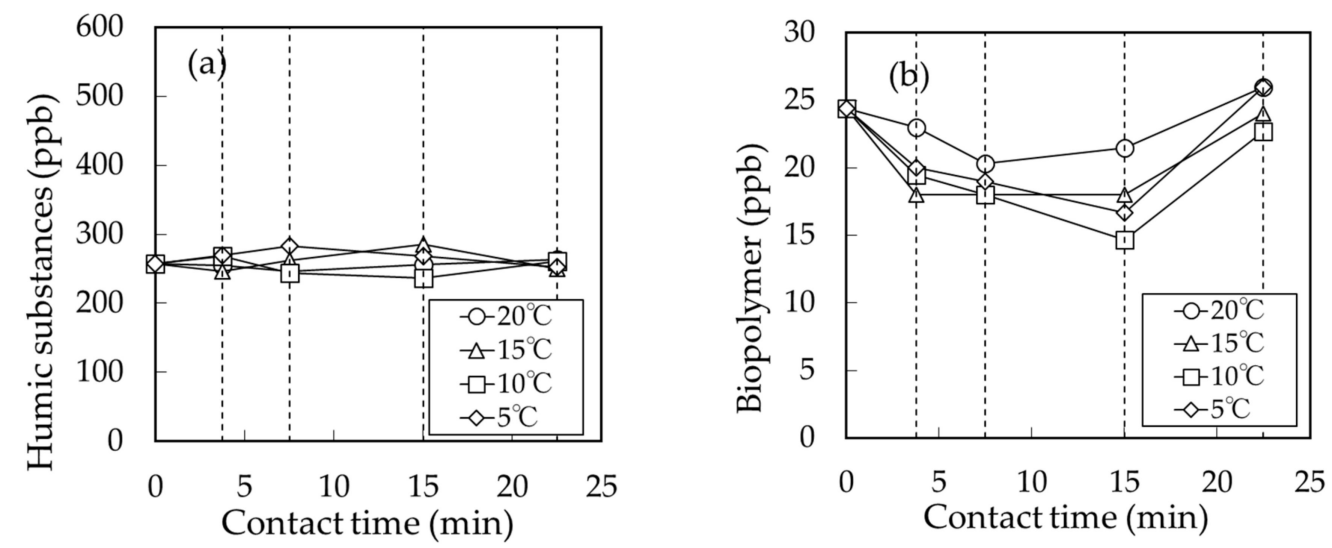

Figure 4. Effect of contact time and operating temperature on the removal of (a) humic substances and (b) biopolymer by the BCF.

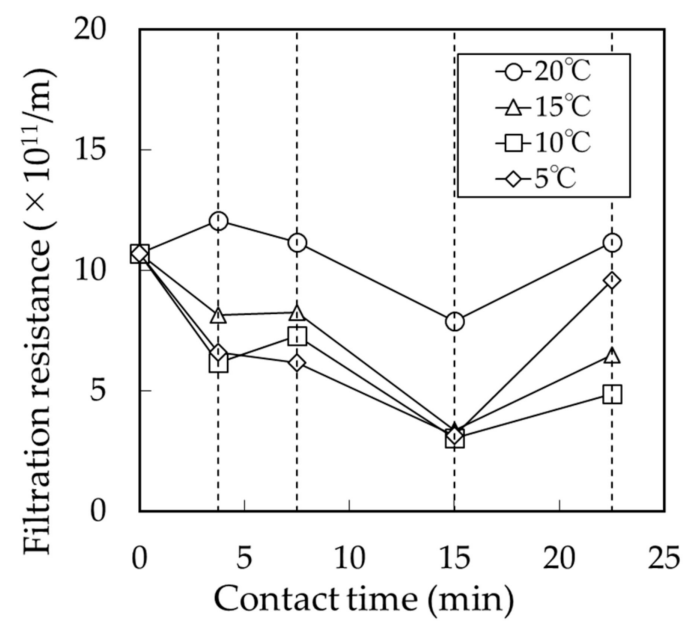

Figure 5. Effect of BCF pretreatment on membrane fouling.

Figure 6 shows the relationship between temperature and biopolymer removal rate, $r_{b}$ $\left(\mathrm{mg} /\left(\mathrm{m}^{3} \cdot\right.\right.$ day $\left.)\right)$ in each contact time of BCF calculated with Equation (2).

$$
r_{b}=Q \times\left(C_{i}-C_{t}\right) / V_{t}
$$

where $Q$ is flow rate $\left(\mathrm{m}^{3} /\right.$ day), $C_{i}$ and $C_{t}$ are the biopolymer concentration $\left(\mathrm{mg} / \mathrm{m}^{3}\right)$ of influent and effluent at contact time, $t$ (day) respectively. $V_{t}$ is the reactor volume $\left(\mathrm{m}^{3}\right)$ for contact time, $t$. It is clear from Figure 6 that the optimum temperature of microorganisms assimilated at low temperature of $5{ }^{\circ} \mathrm{C}$ is around $10^{\circ} \mathrm{C}$, and at $20^{\circ} \mathrm{C}$, the activity of microorganisms to remove biopolymer decreased remarkably. It means that the temperature changes as large as $15^{\circ} \mathrm{C}$ (from 5 to $20^{\circ} \mathrm{C}$ ) caused a decrease of the biopolymer removal and negatively affected the filtration resistance. In general, however, the daily temperature change of raw water is assumed to be within $10^{\circ} \mathrm{C}$. Thus, the daily temperature change of raw water is unlikely to affect the performance of BCFs as a pretreatment strategy. 


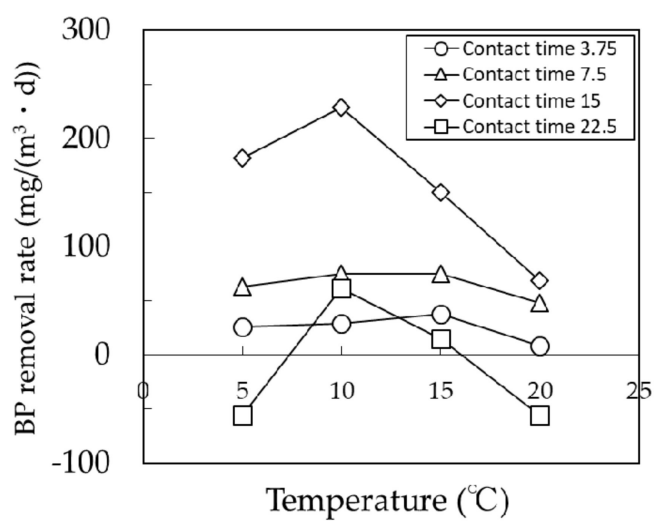

Figure 6. Effect of temperature on biopolymer (BP) removal rate in BCF.

The effect of the BCF treatment on the concentration of humic substances and biopolymers and the filtration resistance was monitored in the Motoyama drinking water treatment plant (Kobe, Japan) to confirm the validity of the laboratory-scale experimental results discussed above. Figure 7 shows the seasonal change of the biopolymer and humic substances in the BCF influent and effluent from this treatment plant, which was operated at the optimum contact time of $15 \mathrm{~min}$. Figure 8 shows the seasonal change of the filtration resistance. Filtration resistance was calculated by Equation (1) using the $20 \mathrm{~h}$ filtration data obtained from the mini MF module test under the conditions listed in Table 1. The experimental data were collected over one year from July 2015 to July 2016.
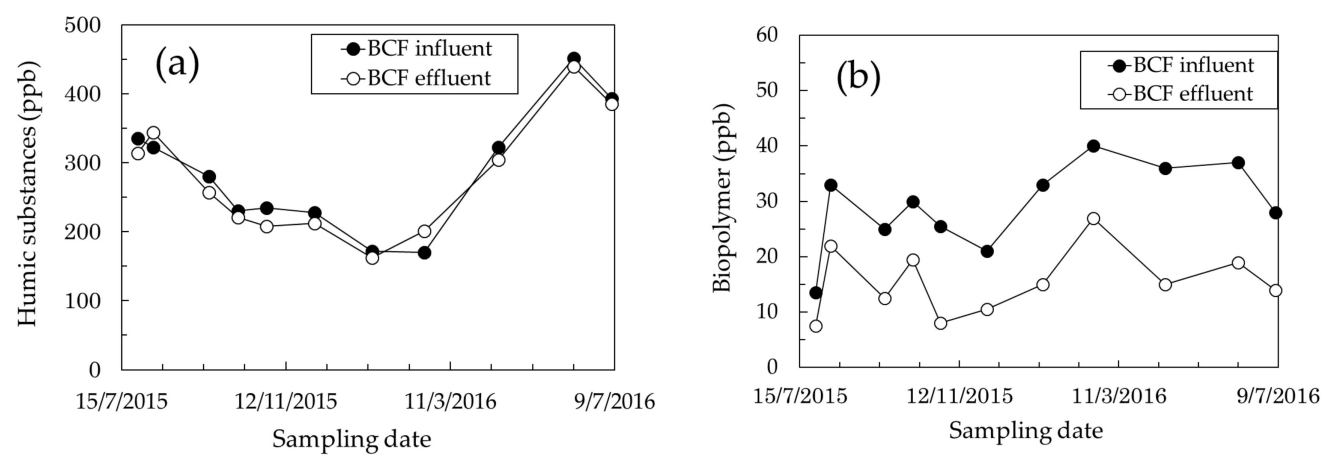

Figure 7. Seasonal change of (a) humic substances and (b) biopolymer in the influent (closed circles) and effluent (open circles) of BCF.

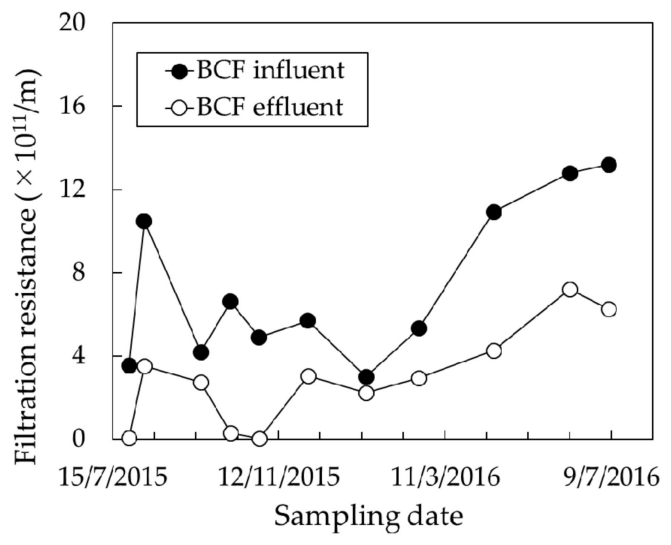

Figure 8. Seasonal change of the filtration resistance of the BCF influent (closed circles) and effluent (open circles). 
Although previous studies have reported humic substances to be a major foulant [11,12], Figure 7 shows that they were not removed by the $\mathrm{BCF}$ throughout the year; in contrast, $\sim 50 \%$ of the biopolymer was removed. Thus, it is clear that the decrease of filtration resistance by BCF treatment was due to the decrease of biopolymer concentration. This result indicates that the biopolymer is the primary influence on membrane fouling in the actual drinking water treatment plant with raw river water. This result is consistent with the report of Kimura et al. [13], who showed an excellent correlation between membrane fouling and biopolymer content in five river waters.

On the other hand, it is found from Figures $7 \mathrm{a}$ and 8 that the seasonal change of the filtration resistance, especially the filtration resistance for BCF influent, is correlated with the seasonal change of humic substances. Probably, this result indicates that humic substances affect the membrane fouling to a certain degree, even though they are not the main foulant.

In this experiment, the biopolymer was removed up to $50 \%$. However, it will be difficult to increase the removal rate of biopolymer further. Because, the decomposition of biopolymer may be increased by increasing the quantity of microorganisms in BCF column and/or by increasing the contact time. However, at the same time, the increase of quantity of microorganisms and the increase of contact time increase the biopolymer produced by microorganisms.

\section{Conclusions}

This study examined the effects of a biological contact filter (BCF) as a pretreatment on reducing membrane fouling in a drinking water treatment system employing a microfiltration (MF) membrane. Specifically, the effect of the BCF on the fouling of the MF membrane was first evaluated using mini module test equipment. On the basis of LC-OCD measurements, it was established that the main membrane foulant was a biopolymer. It was then confirmed that BCF pretreatment reduced the biopolymer concentration, resulting in a reduction of membrane fouling. Notably, the BCF treatment could remove the biopolymers even at $5{ }^{\circ} \mathrm{C}$, a typical winter season temperature. The effect of the $\mathrm{BCF}$ treatment was also verified in an actual drinking water treatment plant. The biopolymer concentration in the BCF column effluent first decreased with a contact time, but then increased; a contact time of 15 min was found to be optimum in this study. The increase of the biopolymer concentration was attributed to its production by microorganisms. Thus, optimizing the contact time of raw water with $\mathrm{BCF}$ is crucial in drinking water treatment systems.

Author Contributions: Susumu Hasegawa, Takuya Iwamoto, Taro Miyoshi, Sosuke Onoda, and Kazushi Morita conceived and designed the experiments; Susumu Hasegawa, Takuya Iwamoto, and Taro Miyoshi performed the experiments; Susumu Hasegawa, Takuya Iwamoto, Taro Miyoshi, and Ryosuke Takagi analyzed the data; Susumu Hasegawa, Ryosuke Takagi and Hideto Matsuyama contributed to the writing manuscript.

Conflicts of Interest: The authors declare no conflicts of interest.

\section{References}

1. Yang, H.; Li, D.; Zhang, J.; Hao, R.; Li, B. Design of biological filter for iron and manganese removal from water. J. Environ. Sci. Health 2004, 39, 1447-1454. [CrossRef]

2. Gao, W.; Liang, H.; Ma, J.; Han, M.; Chen, Z.; Han, Z.; Li, G. Membrane fouling control in ultrafiltration technology for drinking water production: A review. Desalination 2011, 272, 1-8. [CrossRef]

3. Bouwer, E.J.; Crowe, P.B. Biological processes in drinking water treatment. J. Am. Water Works Assoc. 1988, 80, 82-93.

4. Katsoyiannis, I.A.; Zouboulis, A.I. Biological treatment of Mn (II) and Fe (II) containing groundwater: Kinetic consideration and product characterization. Water Res. 2004, 38, 1922-1932. [CrossRef] [PubMed]

5. Tian, J.; Ernst, M.; Cui, F.; Fekel, M. Correlations of relevant membrane foulants with UF membrane fouling in different waters. Water Res. 2013, 47, 1218-1228. [CrossRef] [PubMed]

6. Haberkamp, J.; Ernst, M.; Bockelmann, U.; Szewzyk, U.; Jekel, M. Complexity of ultrafiltration membrane fouling caused by macromolecular dissolved organic compounds in secondary effluents. Water Res. 2008, 42, 3153-3161. [CrossRef] [PubMed] 
7. Miyoshi, T.; Aizawa, T.; Kimura, K.; Watanabe, Y. Identification of proteins involved in membrane fouling in membrane bioreactors (MBRs) treating municipal wastewater. Int. Biodeterior. Biodegrad. 2012, 75, 15-22. [CrossRef]

8. Chen, W.; Westerhoff, P.; Leenheer, J.A.; Booksh, K. Fluorescence excitation-emission matrix regional integration to quantify spectra for dissolved organic matter. Environ. Sci. Technol. 2003, 37, 5701-5710. [CrossRef] [PubMed]

9. Halle, C.; Huck, P.M.; Peldszus, S.; Haberkamp, J.; Jekel, M. Assessing the performance of biological filtration as pretreatment to low pressure membranes for drinking water. Environ. Sci. Technol. 2009, 43, 3878-3884. [PubMed]

10. Peldszus, S.; Halle, C.; Peiris, R.H.; Hamouda, M.; Jin, X.; Legge, R.L.; Budman, H.; Moresoli, C.; Huck, P.M. Reversible and irreversible low-pressure membrane foulants in drinking water treatment: Identification by principal component analysis of fluorescence EEM and mitigation by biofiltration pretreatment. Water Res. 2011, 45, 5161-5170. [CrossRef] [PubMed]

11. Fan, L.; Harris, J.L.; Roddick, F.A.; Booker, N.A. Influence of the characteristics of natural organic matter on the fouling of microfiltration membranes. Water Res. 2001, 35, 4455-4463. [CrossRef]

12. Peiris, R.H.; Jaklewicz, M.; Budman, H.; Legge, R.L.; Moresoli, C. Assessing the role of feed water constituents in irreversible membrane fouling of pilot-scale ultrafiltration drinking water treatment systems. Water Res. 2011, 47, 3364-3374. [CrossRef] [PubMed]

13. Kimura, K.; Tanaka, K.; Watanabe, Y. Microfiltration of different surface waters with/without coagulation: Clear correlations between membrane fouling and hydrophilic biopolymers. Water Res. 2014, 49, 434-443. [CrossRef] [PubMed]

(C) 2017 by the authors. Licensee MDPI, Basel, Switzerland. This article is an open access article distributed under the terms and conditions of the Creative Commons Attribution (CC BY) license (http:/ / creativecommons.org/licenses/by/4.0/). 